\title{
Krabbe disease
}

INSERM

\section{Source}

INSERM. (1999). Orphanet: an online rare disease and orphan drug data base. Krabbe disease. ORPHA:487

Krabbe disease is a lysosomal disorder that affects the white matter of the central and peripheral nervous systems. It includes infantile, late-infantile/juvenile and adult forms. 